
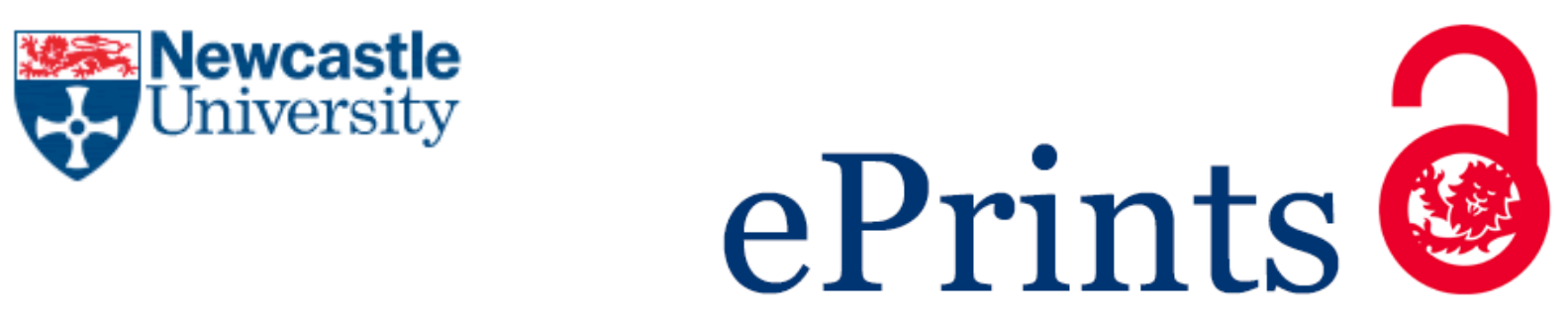
Bonanni L, Francotti R, Nobili F, Kramberger MG, Taylor JP, Garcia-Ptacek S, Falasca WN, Fama F, Cromarty R, Onofrj M, Aarsland D.

EEG Markers of Dementia with Lewy Bodies: A Multicenter Cohort Study. Journal of Alzheimer's Disease 2016, 29(5), 1-9.

\title{
Copyright:
}

This is the authors' accepted manuscript of an article that has been published in its final definitive form by IOS Press, 2016.

DOI link to article:

http://dx.doi.org/10.3233/JAD-160435

Date deposited:

$04 / 11 / 2016$

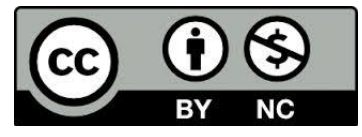

This work is licensed under a Creative Commons Attribution-NonCommercial 3.0 Unported License 


\section{EEG markers of Dementia with Lewy Bodies: a multicenter cohort study}

Bonanni $\mathrm{L}^{1}$, Franciotti $\mathrm{R}^{1}$, Nobili $\mathrm{F}^{2}$, Kramberger $\mathrm{MG}^{3}$, Taylor $\mathrm{JP}^{4}$, Garcia Ptacek $\mathrm{S}^{5}$, Falasca $\mathrm{NW}^{6}$, Famà $\mathrm{F}^{2}$, Cromarty $\mathrm{R}^{4}$, Onofrj $\mathrm{M}^{1}$, Aarsland $\mathrm{D}^{7}$, on behalf of the E-DLB study group*

${ }^{1}$ Department of Neuroscience, Imaging and Clinical Science, and Aging Research Centre, G. d'Annunzio University, Chieti, Italy

${ }^{2}$ Clinical Neurology, Dept of Neuroscience (DINOGMI), University of Genoa and IRCCS AOU San Martino-IST, Genoa, Italy

${ }^{3}$ Department of Neurology, University Medical Centre, Ljubljana, Slovenia

${ }^{4}$ Campus for Ageing and Vitality, Newcastle University, United Kingdom

${ }^{5}$ Department of Neurobiology, Care Sciences and Society, Center for Alzheimer Research, Division of Clinical Geriatrics, Karolinska Institutet, and Memory Clinic Department of Geriatric Medicine, Karolinska University Hospital, Stockholm, Sweden

${ }^{6}$ BIND - Behavioral Imaging and Neural Dynamics Center, University of Chieti-Pescara, Chieti, Italy

${ }^{7}$ King's College of London, UK.

Corresponding Author:

Laura Bonanni

Department of Neuroscience and Imaging

G. d'Annunzio University of Chieti-Pescara

Via dei Vestini

66100 Chieti, Italy

Phone/fax: +39-0871-562019

Email: 1.bonanni@unich.it

Word count: 3500 


\section{Abstract}

Quantitative EEG (QEEG) has demonstrated good discriminative capacity for Dementia with Lewy Bodies (DLB) diagnosis as compared to Alzheimer's Disease (AD) with a predictive value of $100 \%$ in a single cohort study. EEG in DLB was characterized by a dominant frequency (DF) in pre-alpha $(5.5-7.5 \mathrm{~Hz})$, theta, or delta bands and DF variability $(\mathrm{DFV})>1.2 \mathrm{~Hz}$, frequency prevalence $(\mathrm{FP})$ pre-alpha in $>40 \%$ and FP alpha in $<32 \%$ of the epochs.

To validate the aforementioned QEEG findings in independent cohorts of clinically diagnosed DLB vs. AD patients, we analyzed EEG traces of 79 DLB and 133 AD patients (MMSE>20) collected from four European Centers.

EEG traces from 19 scalp derivations were acquired as at least 10 min continuous signals and epoched in off-setting as series of 2 second-long epochs, subsequently processed by Fast Fourier Transform (frequency resolution $0.5 \mathrm{~Hz}$ ).

DLB patients showed EEG specific abnormalities in posterior derivations characterized by $\mathrm{DF}<8 \mathrm{~Hz}$ FP pre-alpha $>50 \%$, FP alpha $<25 \%$. DFV was $>0.5 \mathrm{~Hz}$. AD patients displayed stable alpha DF, DFV $<0.5 \mathrm{~Hz}$, FP pre-alpha $<30 \%$, and FP alpha $>55 \%$.

DLB and AD differed for DF $\left(\mathrm{p}<10^{-6}\right)$, DFV $(\mathrm{p}<0.05)$, FP pre-alpha $\left(\mathrm{p}<10^{-12}\right)$ and FP alpha $\left(\mathrm{p}<10^{-}\right.$ 12). Discriminant analysis detected specific cut-offs for every EEG mathematical descriptor; $D F=8$, $\mathrm{DFV}=2.2 \mathrm{~Hz}$, FP pre-alpha=33\%, FP alpha $=41 \%$ for posterior derivations

If at least one of the cut-off values was met, the percentage of DLB and AD patients correctly classified was $90 \%$ and $64 \%$ respectively.

The findings in this multicenter study support the validity of QEEG analysis as a tool for diagnosis in DLB patients.

Keywords: quantitative EEG, Dementia with Lewy Bodies. 


\section{Introduction}

Dementia with Lewy bodies (DLB) is the second most common cause of neurodegenerative dementia after Alzheimer's disease (AD). Clinically, fluctuations in attention, visual hallucinations and extrapyramidal signs are cardinal features of DLB [1]. However, while neuropathological series have demonstrated high accuracy for the clinical diagnosis of AD [2], the accuracy of the clinical diagnosis of DLB is less satisfactory [3-4-5] because some of the core clinical features may not appear during the entire course of DLB [6] or may overlap with AD [7] . Thus, DLB tends to be underdiagnosed during life and often misdiagnosed as AD [8-9].

In addition, neuropathological findings show that AD and DLB share pathological features linked to amyloid deposition [1] and in vivo, molecular imaging studies, by amyloid positron emission tomography, have confirmed a high prevalence of amyloid load in DLB patient populations [10]. It is important to differentiate between these diseases because DLB patients may be more sensitive to adverse effects of neuroleptics [11], may exhibit faster disease progression [12-13] and different response to acetylcholinesterase inhibitors $[14,15]$ as compared to AD patients.

The accurate differential diagnosis is also particularly relevant for the appropriate selection of patients for clinical trials.

Great emphasis has recently been placed on methods evaluating the uptake of dopamine transporter in basal ganglia [16-17] and the postganglionic sympathetic cardiac innervation[18]. These methods may improve clinical diagnostic accuracy of DLB, but there is a clear need of affordable non invasive markers to assist with accurate identification of this entity.

Several studies from small cohorts suggested that EEG, analyzed in a variety of quantitative methods, is able to differentiate DLB from AD from the very early disease stages with high specificity and sensitivity [19-23]. These EEG alterations are highly correlated with the presence of fluctuating cognition [19-22]. 
However, the aforementioned results were never replicated in larger cohorts, and this limited the generalizability of the conclusions.

In a previous study [21], in an attempt to differentiate DLB from AD patients on the basis of EEG characteristics, the highest statistical yields were obtained in the comparison of EEG variables measured on recordings from posterior derivations.

AD patients presented with an EEG pattern characterized by alpha Dominant frequency (DF) prevalent in $>55 \%$ of the EEG epochs and DF variability (DFV) $<1.2 \mathrm{~Hz}$. By contrast, DLB patients presented with derangement of EEG background activity, characterized by DF in bands lower than alpha (i.e. pre-alpha, theta, delta) with $\mathrm{DFV}>1.2 \mathrm{~Hz}$, pre-alpha frequency prevalence (FP) in $>40 \%$ of the analyzed EEG epochs, and alpha FP in $<32 \%$. [21]. In that study these features were able to fully differentiate between DLB and AD.

The aim of the present study is to test the robustness of the previously developed EEG method of analysis in a multicenter setting without harmonization of the recordings.

\section{Materials and Methods}

Study design

We analysed EEG traces of 79 patients with probable DLB [1] and 133 AD [24] from 4 different European Centers involved in a European multicenter DLB study (E-DLB): 1. Clinical Neurology Unit, Department of Neuroscience (DINOGMI), University of Genoa, Italy; 2. Memory clinic at Karolinska University Hospital, Huddinge, Sweden; 3. Institute of Neuroscience, Newcastle University, Newcastle upon Tyne, UK, 4. Department of Neurology, University Medical center Ljubljana, Slovenia.

EEG recordings were obtained at each centers but analyzed centrally at the Department of Neuroscience, Imaging and Clinical Science, and Aging Research Centre, G. d'Annunzio University, Chieti, Italy. 
Diagnostic and clinical examination

The diagnosis of DLB was made according to consensus criteria [1] by expert clinicians.

Demographics and clinical procedures were not harmonized across centres, but at all centres the assessment included a detailed history with questions on previous diseases, drug history; and physical, neurological, and psychiatric examinations using standardized scales such as the motor subscale of the Unified Parkinson's Disease Rating Scale and the Neuropsychiatric Inventory. Routine blood tests, brain imaging and neuropsychological testing were available, including assessment of REM sleep Behavior Disorder (RBD) [25]. Dopamine transporter SPECT scans ((123) I-FP CIT SPECT) were performed in 38 (48\%) DLB patients, and 36 (95\%) were rated as abnormal.

Cognition was assessed using the Mini-Mental State Examination (MMSE) in 162 patients, or the Montreal Cognitive Assessment (MOCA) [26] in 60 patients. To be able to compare cognitive data, the MOCA score was converted to an equivalent MMSE score [27].

Local ethics committees at the individual centres approved the study. The patients signed an informed consent.

Drug withdrawal and caffeine, nicotine and alcohol prohibition for at least $48 \mathrm{~h}$ prior to EEG recording were performed only in one Center.

\section{EEG recordings}

Quantitative EEGs were recorded with $\mathrm{Ag} / \mathrm{AgCl}$ disk scalp electrodes from 19 scalp derivations placed according to the international 10-20 system, or with 128 scalp derivations and two additional electrodes placed on A1 and A2. Nineteen electrodes from Fp1, Fp2, Fz, F3, F4, F7, F8, Cz, C3, C4, Pz, P3, P4, T3, T4, T5, T6, O1, and O2 were considered for the analysis. EEG activity was analysed from single or multiple leads grouped to define the following scalp regions: anterior (Fz, Fp2, F7, Fp1, F3, F4, F8), posterior (Pz, P3, P4, O1, O2), temporal (T3, T4, T5, T6). 
Recordings were acquired continuously with subjects resting comfortably, with their eyes closed.

\section{EEG analysis}

EEG analyses were fully computerized and performed by experimenters blind to clinical diagnosis. Ninety blocks of artefact-free 2 second-long epochs appearing consecutively were selected off-line by visual inspection. Fast Fourier Transform (FFT) was applied on each epoch allowing a frequency resolution of $0.5 \mathrm{~Hz}$. The obtained spectra values were then processed in order to compute a mean Power Spectrum (mPS) for each channel and expressed in $\mu \mathrm{V}^{2}$. The mPS was divided automatically into 4 frequency bands (3-4 Hz (delta), 4.5-5.5 Hz (theta), 6-7.5 Hz (pre-alpha), 8-12 Hz (alpha).[19]

$\mathrm{DF}$, i.e. the frequency where the spectral power value was greatest, was evaluated for each epoch. Single channel power spectra were represented as Compressed Spectral Arrays (CSA) showing the sequences of absolute or relative power spectra values in each of the 90 analysed epochs.

CSA is the epoch to epoch representation of FFT values, for each derivation. It shows peaks of amplitudes, corresponding to frequencies in a single epoch [28]. These peaks of amplitude could either be stable through time or change (i.e. different frequencies could have the highest amplitude through time). CSAs can be quantified by the following mathematical descriptors: a) DF, b) FP, i.e. percent of epochs where a dominant frequency band was observed (1-100\%), c) DFV expressing the variability of DF across the 90 analyzed epochs [21].

DF, DFV, FP were translated into five patterns of EEG activity. [21]

The first pattern (CSA pattern 1, Stable alpha) was defined as characterized by all the following variables: dominant alpha in $\geq 60 \%$ of analyzed epochs (DF $\geq 8 \mathrm{~Hz}, \mathrm{FP}$ alpha $\geq 60 \%$ ), DFV of alpha $<0.6 \mathrm{~Hz}$, mean DFV of all epochs $<1.6 \mathrm{~Hz}$.

The second pattern (CSA pattern 2, unstable alpha with pre-alpha or theta/delta) consisted of all the following: dominant alpha in $<50 \%$ of epochs, dominant pre-alpha or theta $(4.5-7.5 \mathrm{~Hz})$ in $\geq 40 \%$ of epochs (FP pre-alpha $>40 \%$ ), mean DFV >2 Hz. . 
The third pattern (CSA pattern 3, stable pre-alpha) consisted of all the following: absence of alpha, stable pre-alpha, in $\geq 70 \%$ of analyzed epochs, DFV of the analyzed epochs $<1.0 \mathrm{~Hz}$. The fourth pattern (CSA pattern 4, unstable pre-alpha with theta/delta) consisted of: absence of alpha, dominant pre-alpha in $<70 \%$ of analyzed epochs, dominant theta or delta in $\geq 40 \%$ of epochs, $\mathrm{DFV}>2.0 \mathrm{~Hz}$.

The last pattern (CSA pattern 5, unstable low frequency) consisted of absence of alpha/pre-alpha, delta dominant activity in $>2$ subsequent epochs with DFV $>4 \mathrm{~Hz}$.

In our previous study DLB patients showed a CSA pattern ranging from 2 to 5 . AD patients had a CSA pattern 1. Thus, CSA patterns together with DF, DFV and FP from posterior derivations, which showed to have the highest statistical yields in the original study, were chosen as the primary outcome variables in the current study. We also analysed CSA patterns with DF, DFV and FP recorded from anterior and temporal scalp derivations.

\section{Statistics}

Demographic and clinical differences between the two groups were assessed with the independent $t$ test for continuous data that passed normality testing by Kolmogorov-Smirnov test and Levene's test for equality of variances between groups. $\chi 2$ test was performed for categorical data. Independent $t$ test was performed on DF and DFV; analysis of variance (ANOVA) was performed on FP with group as categorical variable and FP as factor with four levels (FP in delta, theta, prealpha and alpha band). Bonferroni test was used for post-hoc analysis and the level of statistical significance was set at $5 \%(\mathrm{p}=0.05)$. We also performed a comparative analysis between all the EEG variables derived from the present study and those from the previous study. [21] A receiver operating characteristic (ROC) analysis was performed to determine new cut-off values for each EEG variable for single-patient classification and to estimate the best EEG variable to distinguish DLB from AD patients. Sensitivity and specificity were recalculated according to the new cut-off values. 
Discriminant analysis with stepwise statistics was also used to test the hypothesis that the EEG categorization could separate the two diagnostic groups.

The analyses were also performed on DLB patients as compared to a numerically equal group of AD patients matched with DLB patients for age, sex, education, MMSE and NPI total scores, randomly selected among the AD sample.

\section{Results}

The demographic and clinical characteristics of the total and centre-specific samples are shown respectively in Table 1 and in supplementary table 1 . DLB group was younger $(p=0.005)$ and included more males $(\mathrm{p}=0.01)$ compared to the $\mathrm{AD}$ group.

As reported in Table 2, DLB and AD groups differed for DF, FP pre-alpha and FP alpha values in all the derivations explored (anterior, posterior and temporal) and for DFV values only in posterior derivations.

Supplementary table 2 shows a comparative analysis between the aforementioned results and the corresponding results obtained in the original EEG study [21].

Figure 1 shows FP values in delta, theta, pre-alpha and alpha band in anterior, temporal and posterior derivation for DLB and AD groups, and demonstrates that FP was highest in the pre-alpha band in DLB $\left(\mathrm{p}<10^{-12}\right.$ in the comparison of DLB vs. AD in temporal and posterior derivations, $\mathrm{p}<10^{-9}$ in anterior derivations), whereas it was in the alpha band in $\operatorname{AD}\left(\mathrm{p}<10^{-12}\right.$ in the comparison of DLB vs. AD in temporal and posterior derivations, $\mathrm{p}<10^{-9}$ in anterior derivations) in all the derivations explored.

ROC curve analysis on EEG variables showed the cut-off values reported in table 3, together with sensitivity, specificity, positive predictive values (PPV) and negative predictive values (NPV) of the EEG variables according to the reported cut-offs. The highest sensitivity was found in anterior derivations, whereas EEG variables values from posterior derivations were more specific. NPV values were higher than PPV for every EEG variable. 
Sensitivity and specificity of EEG variables were also tested with the cut-off values described in the previous EEG study [21]. Results are reported in supplementary table 3. In particular, cut-off for DFV was higher in the present study as compared to the previous study; FP pre-alpha was lower in the present study as compared to the previous study. Cut-off for CSA pattern was $>2$ in the present study while it was $>1$ in the previous study (table 3 and supplementary table 3 ).

When combining all the EEG variables $(\mathrm{DF}<7.8 \mathrm{~Hz}, \mathrm{DFV}>2.2 \mathrm{~Hz}$, FP pre-alpha $>32.7 \mathrm{~Hz}$, FP alpha $<40.7 \mathrm{~Hz}$, CSA pattern >2) the sensitivity reached $90 \%$ and specificity reached $64 \%$ in the comparison between DLB and AD patients.

Linear discriminant analysis applied on EEG variables indicated that the best discriminating variable between DLB and AD patients was FP in alpha band in all the derivations explored (Wilks' lambda $=0.75,0.70$ and $0.67 ; \mathrm{F}=69,89$ and 104 , respectively for anterior, temporal and posterior derivations; $\mathrm{p}<10^{-4}$ for all the derivations).

Figure 2 shows ROC curves and Area Under Curve (AUC) values for each EEG variable from all the derivations.

Among the 36 patients with positive (123) I-FP-CIT SPECT scan, only 3 could not be correctly classified as DLB according to EEG variables. On the other hand, the two patients with negative (123)I-FP-CIT SPECT scan had an EEG pattern suggestive of a DLB diagnosis. By combining EEG with (123) I-FP-CIT SPECT scan, the percentage of DLB patients correctly classified reached $100 \%$.

Statistical comparisons of EEG variables between DLB patients with positive (123) I-FP-CIT SPECT scan and AD patients showed significant differences and are reported in supplementary table 4 .

Statistical comparisons of EEG variables between DLB patients with positive (123) I-FP-CIT SPECT scan and DLB patients without (123) I-FP-CIT SPECT scan evaluation showed significant differences of DFV from posterior derivations $(F(1,75)=4.1 \mathrm{p}<0.05)$. Specifically DFV was greater in DLB with positive (123) I-FP-CIT SPECT scan $(0.9 \pm 0.2 \mathrm{~Hz})$ than DLB without (123) I-FP-CIT 
SPECT scan evaluation $(0.4 \pm 0.1 \mathrm{~Hz})$. No significant differences were found in the comparison of EEG variables from anterior and temporal derivations.

Discriminant analysis on the EEG variables of the 36 patients with positive (123) I-FP-CIT SPECT scan vs. the $133 \mathrm{AD}$ patients showed different cut-off values and higher sensitivity values as compared to discriminant analysis on the 79 DLB vs. the 133 AD patients. Results of the ROC analysis are reported in supplementary figure 1. Supplementary table 5 reports sensitivity, specificity, PPV and NPV values.

Finally, to test for the use of drug treatment during the EEG recordings as a potential confounder, a statistical comparisons on EEG variables was performed between patients who were under treatment during EEG recording and patients where drug treatments were withdrawn before EEG. No significant differences were found in DLB group, whereas AD patients who underwent drug withdrawal before EEG had higher DF $(\mathrm{p}=0.001)$ and higher FP in alpha band $\left(\mathrm{p}<10^{-4}\right)$ in posterior derivations as compared to AD patients who did not withdraw drug treatments. Significant results of the statistical comparisons are summarized in supplementary table 6.

To verify whether our results were not biased by the possible contribution of age, sex, and education, we also performed the aforementioned analyses on DLB patients in comparison to a numerically equal number of $\mathrm{AD}$ patients matched for age, sex, education, MMSE and NPI total scores (supplementary table 7). No differences were found between the analyses performed on the whole patient samples and the analyses performed on the matched samples. Results of the comparisons between the two matched groups are reported in supplementary tables 8 and 9 . In the selected sample, when combining all the EEG variables $(\mathrm{DF}<7.8 \mathrm{~Hz}, \mathrm{DFV}>2.3 \mathrm{~Hz}$, FP prealpha $>31.6 \mathrm{~Hz}, \mathrm{FP}$ alpha $<40.7 \mathrm{~Hz}, \mathrm{CSA}$ pattern $>1$ ) the sensitivity reached $92 \%$ and specificity reached $61 \%$ in the comparison between DLB and AD patients.

Linear discriminant analysis applied on EEG variables from the selected subgroup of patients indicated that the best discriminating variable between DLB and AD patients was FP in alpha band in all the derivations explored (as in the total sample) (Wilks' lambda $=0.77,0.71$ and $0.68 ; \mathrm{F}=46$, 
64 and 74, respectively for anterior, temporal and posterior derivations; $p<10^{-4}$ for all the derivations).

\section{Discussion}

In this international multi-centre study based on routine clinical EEG recording, we demonstrate the discriminative power of automated EEG analysis to differentiate between DLB and AD. These results support our previous conclusions from a single-centre study suggesting that quantitative assessment of DF, DFV and FP and qualitative assessment CSA specific patterns could accurately discriminate between DLB and AD [21].

The present study confirms the best discriminative performance of the analysis of posterior derivations (table 2 and supplementary table 2).

The inclusion of a larger population of AD and DLB patients from different European centers allowed us to better estimate cut-off and sensitivity values for EEG variables, reaching $90 \%$ of correct classification of DLB patients when combining all EEG variables.

The sensitivity of (123) I-FP-CIT SPECT scan, which is considered the gold standard for the in vivo diagnosis of DLB, reached 95\%. By combining EEG with (123)I-FP-CIT SPECT scan, the percentage of DLB patients correctly classified reached $100 \%$.

The combination of EEG variables reached high sensitivity (90\%), but the specificity was low (64\%) in comparison with AD patients. Previous findings [21] showed better specificity values due to the high percentage (100\%) of AD patients which had CSA pattern 1 in posterior derivations, whereas in the present study only $60 \%$ of AD patients had a CSA pattern 1 in posterior derivations (see supplementary table 2 for further details).

A possible explanation for the low specificity of EEG results is that in the original study the patient selection method was particularly focused on the presence of fluctuating cognition: we operationally selected $\mathrm{AD}$ patients without any symptom suggestive of the presence of fluctuating cognition. All AD patients had a score 0 at the CAF questionnaire and the EEG abnormalities found 
in the DLB cohort were strongly correlated with CAF scores. This correlation was further confirmed in a cohort of MCI subjects converting to DLB. [29]

In the present study CAF scores were available only in a minority of patients (supplementary table $1)$.

An alternative explanation is that DLB diagnoses were based on clinical features, with no neuropathological confirmation. Our DLB patients were strictly evaluated for the presence of distinctive features (which if not sensitive are however specific), were diagnosed and followed at tertiary centers, and most of the patients had a positive (123) I-FP CIT SPECT scan to support diagnosis. However, the criteria for clinical diagnosis of DLB have low sensitivity [1], indicating that the diagnosis is often missed especially in the early stages when the frequency of patients presenting core symptoms is low.

Even DAT SPECT, which has high sensitivity and specificity for DLB vs. AD diagnosis, presents a percentage of false negative cases [30] and can be positive in other dementia than DLB, such as frontotemporal dementia. [31]

Therefore it is possible that a small percentage of clinically diagnosed AD patients showing an EEG pattern typical of DLB were actually DLB.

There is a small percentage of cases with clinical features of DLB who show a normal striatal captation at (123) I-FP-CIT SPECT scan. It has been suggested that some of these patients may not have involvement of dopaminergic neurons in the substantia nigra, at least in the earliest stages.

Some DLB patients indeed never develop parkinsonism [33] and in some cases, Lewy-body pathology does not follow the Braak pathway of deposition and can be found in the cortex and higher brain stem, but at a lesser extent in the lower brain stem. [34-35]

We suggest that EEG could be especially useful to diagnose DLB in those patients with early cortical involvement and relative sparing of substantia nigra. 
An alternative explanation could be that our AD patients were older and more cognitively impaired as compared to DLB, thus likely to show signs of EEG rhythm disruption, as also shown in our previous study where differences of EEG parameters between DLB and AD patients at two-year follow-up were blurred. [21]

Other methodological limitations need to be discussed:

The first methodological issue to account for is inherent to the study design. The present is a retrospective study on a multicenter cohort of DLB patients who were recruited and followed for many different reasons than performing an EEG study. Therefore, we did not exclude patients who were under pharmacological treatments at the time of EEG recordings. The absence of perfect harmonization of EEG acquisition, including drug withdrawal before EEG recording (which was only performed in one center) might have obscured some of the differences between DLB and AD patients.

However, the aim of the study was to test the robustness of the methods in a real-life setting, thus we believe that this limitation actually strengthens the findings.

A confirmation of the validity of the EEG analysis comes also from the correspondence between results from the total sample (table 2 and 3) and results obtained in the comparison of EEG from the DLB sample with EEG from a numerically equal subgroup of AD patients matched with DLB patients for age, sex, education, MMSE and NPI scores (supplementary table 8 and 9).

Data on pharmacological treatment were not fully available. This might have partially influenced the findings. However, since most DLB and AD patients were on cholinesterase inhibitor treatment and especially because cholinesterase inhibitors have been shown to reduce both fluctuating cognition and EEG abnormalities, [36] it is likely again that, if there was an influence on the results, it was toward a more conservative estimate, causing a reduction of both sensitivity and specificity. This hypothesis was confirmed by the comparison between patients who underwent drug withdrawal vs. patients who did not (supplementary table 6). 
Furthermore, the EEG abnormalities are dynamic (across time) and showed spatial differences across the scalp, with prominent abnormalities in posterior derivations (table 2 and supplementary table 2), thus unlikely to be fully explained by pharmacological treatments, which would have probably smoothened inter-regional differences.

We therefore believe that also this limitation strengthens the findings, since our results likely represent a conservative estimate. It is possible that higher accuracy could be achieved with harmonized clinical and EEG procedures.

We would like to highlight the presence of a specific fast theta band, which we named as pre-alpha in the DLB group. This band was deemed to be especially specific for DLB diagnosis in the previous EEG cohort study [21] and this finding was further confirmed in this multi-centre study. A possible pathophysiological explanation of the peculiar appearance of a dominant fast theta rhythm in DLB patients relies on the role of thalamic neurons, in the genesis of different oscillatory states, including transitions during the normal sleep-wake cycle and acute cognitive enhancements such as improved working-memory and sustained attention. [37] There are some situations, such as deafferentation syndromes, where a set of neurons in the thalamus displays low rhythmicity in a fast theta band in an otherwise awake brain state. In such cases, a dysrhythmic state in a portion of the thalamocortical system is trapped in spindlelike activity, whereas the rest of the system remains in the usual waking state. [38] There is therefore a close relationship among specific thalamic neurons activity, their associated rhythms, and different states of consciousness.

Interestingly, DLB patients present with specific symptoms characterized by clouding of consciousness (fluctuating cognition) [1], sleep disturbances (mind-body dissociation), visual hallucinations (within-mind dissociation), [39] which have all being demonstrated to be associated with abnormalities of thalamic nuclei or thalamo-cortical connectivity. [40-41] The presence of fast theta (pre-alpha) rhythm is thought to be generated in the medial pulvinar nuclei, which are connected with the parieto-occipital cortex, the very same regions both involved 
in the genesis of specific clinical symptoms, e.g. visual hallucinations [42], and showing the presence of specific abnormal EEG rhythms, thus confirming an important role of dysfunctions of thalamo-cortical connections in the genesis of DLB clinical features.

In conclusion our study supports EEG as a helpful tool in the diagnosis of DLB [1] and fosters a large prospective multicenter trial to conclusively define the sensitivity and specificity of the method and to possibly standardize the method of EEG recording and analysis across centers.

\section{Acknowledgments}

The research did not benefit of any financial or material support. 


\section{References}

[1] McKeith IG, Dickson DW, Lowe J, Emre M, O'Brien JT, Feldman H, Cummings J, Duda JE, Lippa C, Perry EK, Aarsland D, Arai H, Ballard CG, Boeve B, Burn DJ, Costa D, Del Ser T, Dubois B, Galasko D, Gauthier S, Goetz CG, Gomez-Tortosa E, Halliday G, Hansen LA, Hardy J, Iwatsubo T, Kalaria RN, Kaufer D, Kenny RA, Korczyn A, Kosaka K, Lee VM, Lees A, Litvan I, Londos E, Lopez OL, Minoshima S, Mizuno Y, Molina JA, Mukaetova-Ladinska EB, Pasquier F, Perry RH, Schulz JB, Trojanowski JQ, Yamada M; Consortium on DLB (2005) Diagnosis and management of dementia with Lewy bodies: third report of the DLB Consortium. Neurology 65, 1863-1872. Erratum in: Neurology 65, 1992.

[2] Kosunen O, Soininen H, Paljarvi L, Heinonen O, Talasniemi S, Riekkinen PJ (1996) Diagnostic accuracy of Alzheimer's disease: a neuropathological study. Acta Neuropathol (Berl) 91, 185-193.

[3] Litvan I, MacIntyre A, Goetz CG, Wenning GK, Jellinger K, Verny M, Bartko JJ, Jankovic J, McKee A, Brandel JP, Chaudhuri KR, Lai EC, D'Olhaberriague L, Pearce RK, Agid Y (1998) Accuracy of the clinical diagnoses of Lewy body disease, Parkinson disease, and dementia with Lewy bodies: a clinicopathologic study. Arch Neurol 55, 969-978.

[4] Hohl U, Tiraboschi P, Hansen LA, Thal LJ, Corey-Bloom J (2000) Diagnostic accuracy of dementia with Lewy bodies. Arch Neurol 57, 347-351.

[5] Nelson PT, Schmitt FA, Jicha GA, Kryscio RJ, Abner EL, Smith CD, Van Eldik LJ, Markesbery WR (2010) Association between male gender and cortical Lewy body pathology in large autopsy series. J Neurol. 257, 1875-1881. 
[6] Merdes AR, Hansen LA, Jeste DV, Galasko D, Hofstetter CR, Ho GJ, Thal LJ, Corey-Bloom J (2003) Influence of Alzheimer pathology on clinical diagnostic accuracy in dementia with Lewy bodies. Neurology 60, 1586-1590.

[7] Walker Z, Jaros E, Walker RWH, Lee L, Costa DC, Livingston G, Ince PG, Perry R, McKeith I, Katona CL (2007) Dementia with Lewy bodies: a comparison of clinical diagnosis, (123)I-FP-CIT SPECT SPECT imaging and autopsy. J Neurol Neurosurg Psychiatry 78, 1176-1181.

[8] Toledo JB, Cairns NJ, Da X, Chen K, Carter D, Fleisher A, Householder E, Ayutyanont N, Roontiva A, Bauer RJ, Eisen P, Shaw LM, Davatzikos C, Weiner MW, Reiman EM, Morris JC, Trojanowski JQ; Alzheimer's Disease Neuroimaging Initiative (ADNI) (2013) Clinical and multimodal biomarker correlates of ADNI neuropathological findings. Acta Neuropathol Commun 1,65 .

[9] Walker Z, Possin KL, Boeve BF, Aarsland D (2015) Lewy body dementias. Lancet 386, 16831697.

[10] Petrou M, Dwamena BA, Foerster BR, MacEachern MP, Bohnen NI, Müller ML, Albin RL, Frey KA (2015) Amyloid deposition in Parkinson's disease and cognitive impairment: a systematic review. Mov Disord 30, 928-935.

[11] Ballard C, Grace J, McKeith I, Holmes C (1998) Neuroleptic sensitivity in dementia with Lewy bodies and Alzheimer's disease. Lancet 351, 1032-1033. 
[12] Olichney J, Galasko D, Salmon R, Hofstetter CR, Hansen LA, Katzman R, Thal LJ (1998)

Cognitive decline is faster in the Lewy body variant of Alzheimer's disease. Neurology 51, 351357.

[13] Rongve A, Vossius C, Nore S, Testad I, Aarsland D (2014) Time until nursing home admission in people with mild dementia: comparison of dementia with Lewy bodies and Alzheimer's dementia. Int J Geriatr Psychiatry 29, 392-398.

[14] Stubendorff K, Larsson V, Ballard C, Minthon L, Aarsland D, Londos E 2014 Treatment effect of memantine on survival in dementia with Lewy bodies and Parkinson's disease with dementia: a prospective study. BMJ Open 4, e005158.

[15] Walker Z, Costa DC, Walker RW, Shaw K, Gacinovic S, Stevens T, Livingston G, Ince P, McKeith IG, Katona CL (2002) Differentiation of dementia with Lewy bodies from Alzheimer's disease using a dopaminergic presynaptic ligand. J Neurol Neurosurg Psychiatry 73, 134-140.

[16] Boot BP (2015) Comprehensive treatment of dementia with Lewy bodies. Alzheimers Res Ther. 7, 45 .

[17] O’Brien JT, Colloby S, Fenwick J, Williams DE, Firbank M, Burn D, Aarsland D, McKeith IG (2004) Dopamine transporter loss visualized with FP-CIT SPECT in the differential diagnosis of dementia with Lewy bodies. Arch Neurol 61, 919-925.

[18] Yoshita M, Taki J, Yokoyama K, Noguchi-Shinohara M, Matsumoto Y, Nakajima K, Yamada M (2006) Value of 123I-MIBG radioactivity in the differential diagnosis of DLB from AD. Neurology 66, 1850-1854. 
[19] Walker MP, Ayre GA, Cummings JL, Wesnes K, McKeith IG, O’Brien JT, Ballard CG (2000) Quantifying fluctuation in dementia with Lewy bodies, Alzheimer's disease, and vascular dementia. Neurology 54, 1616-1625.

[20] Franciotti R, Iacono D, Della Penna S, Pizzella V, Torquati K, Onofrj M, Romani GL (2006) Cortical rhythms reactivity in AD, DLB and normal subjects: a quantitative MEG study. Neurobiol Aging 27, 1100-1109.

[21] Bonanni L, Thomas A, Tiraboschi P, Perfetti B, Varanese S, Onofrj M (2008) EEG comparisons in early Alzheimer's disease, dementia with Lewy bodies and Parkinson's disease with dementia patients with a 2-year follow-up. Brain 131, 690-705.

[22] Andersson M, Hansson O, Minthon L, Rosén I, Londos E (2008) Electroencephalogram variability in dementia with Lewy bodies, Alzheimer's disease and controls. Dement Geriatr Cogn Disord 26, 284-290.

[23] Valladares-Neto DC, Buchsbaum MS, Evans WJ, Nguyen D, Nguyen P, Siegel BV, Stanley J, Starr A, Guich S, Rice D (1995) EEG delta, positron emission tomography, and memory deficit in Alzheimer's disease. Neuropsychobiology 31, 173-181.

[24] McKhann GM (2011) Changing concepts of Alzheimer disease. JAMA 305, 2458-2459.

[25] World Health Organization (1992) The ICD-10 classification of mental and behavioural disorders. Geneva: WHO. 
[26] Nasreddine ZS, Phillips NA, Bédirian V, Charbonneau S, Whitehead V, Collin I, Cummings

JL, Chertkow H (2005) The Montreal Cognitive Assessment, MoCA: a brief screening tool for mild cognitive impairment. Journal of the American Geriatrics Society 53, 695-699.

[27] Steenoven I, Aarsland D, Hurtig H, Chen-Plotkin A, Duda JE, Rick J, Chahine LM, Dahodwala N, Trojanowski JQ, Roalf DR, Moberg PJ, Weintraub D (2014) Conversion between Mini-Mental State Examination, Montreal Cognitive Assessment, and Dementia Rating Scale-2 scores in Parkinson's disease. Mov Dis 29, 1809-1815.

[28] Bickford RG, Brimm J, Berger L, Aung M (1973) Application of compressed spectral array in clinical EEG. In: Kellaway P, Peterse'n I, editors. Automation of clinical electroencephalography. New York: Raven, p. 55-64.

[29] Bonanni L, Perfetti B, Bifolchetti S, Taylor JP, Franciotti R, Parnetti L, Thomas A, Onofrj M (2015) Quantitative electroencephalogram utility in predicting conversion of mild cognitive impairment to dementia with Lewy bodies. Neurobiol Aging 36, 434-445.

[30] Siepel FJ, Rongve A, Buter TC, Beyer MK, Ballard CG, Booij J, Aarsland D (2013) (123)IFP-CIT SPECT in suspected dementia with Lewy bodies: a longitudinal case study. BMJ Open 3, e002642.

[31] Morgan S1, Kemp P, Booij J, Costa DC, Padayachee S, Lee L, Barber C, Carter J, Walker Z (2012) Differentiation of frontotemporal dementia from dementia with Lewy bodies using FP-CIT SPECT. J Neurol Neurosurg Psychiatry 83, 1063-1070. 
[32] van der Zande JJ, Booij J, Scheltens P, Raijmakers PG, Lemstra AW (2016) [123]I-FP-CIT

SPECT scans initially rated as normal became abnormal over time in patients with probable dementia with Lewy bodies. Eur J Nucl Med Mol Imaging Jan 30.

[33] Ballard CG, Aarsland D, McKeith I, O'Brien J, Gray A, Cormack F, Burn D, Cassidy T, Starfeldt R, Larsen JP, Brown R, Tovee M (2002) Fluctuations in attention: PD dementia vs DLB with parkinsonism. Neurology 59, 1714-1720.

[34] Colloby SJ, McParland S, O'Brien JT, Attems J (2012) Neuropathological correlates of dopaminergic imaging in Alzheimer's disease and Lewy body dementias. Brain 135, 2798-2808.

[35] Halliday GM, McCann H (2010) The progression of pathology in Parkinson's disease. Ann N Y Acad Sci 1184, 188-195.

[36] Onofrj M, Thomas A, Iacono D, Luciano AL, Di Iorio A (2003) The effects of a cholinesterase inhibitor are prominent in patients with fluctuating cognition: a part 3 study of the main mechanism of cholinesterase inhibitors in dementia. Clin Neuropharmacol 26, 239-251.

[37] Magnin M, Rey M, Bastuji H, Guillemant P, Mauguière F, Garcia-Larrea L (2010) Thalamic deactivation at sleep onset precedes that of the cerebral cortex in humans. Proc Natl Acad Sci US A 107, 3829-3833.

[38] Steriade M (2006) Grouping of brain rhythms in corticothalamic systems. Neuroscience 137, $1087-1106$. 
[39] Antelmi E, Ferri R, Iranzo A, Arnulf I, Dauvilliers Y, Bhatia KP, Liguori R, Schenck CH, Plazzi G (2015) From state dissociation to status dissociatus. Sleep Med Rev 28, 1-13.

[40] Delli Pizzi S, Maruotti V, Taylor JP, Franciotti R, Caulo M, Tartaro A, Thomas A, Onofrj M, Bonanni L (2014) Relevance of subcortical visual pathways disruption to visual symptoms in dementia with Lewy bodies. Cortex 59, 12-21.

[41] Delli Pizzi S, Franciotti R, Taylor JP, Thomas A, Tartaro A, Onofrj M, Bonanni L (2015) Thalamic Involvement in Fluctuating Cognition in Dementia with Lewy Bodies: Magnetic Resonance Evidences. Cereb Cortex 25, 3682-3689.

[42] O’Brien JT, Colloby SJ, Pakrasi S, Perry EK, Pimlott SL, Wyper DJ, McKeith IG, Williams ED (2008) Nicotinic alpha4beta2 receptor binding in dementia with Lewy bodies using 123I-5IA85380 SPECT demonstrates a link between occipital changes and visual hallucinations. Neuroimage 40, 1056-1063. 
Table 1 Demographic and clinical characteristics (mean \pm S.E.) of the total samples.

\begin{tabular}{llll} 
& DLB $(\mathrm{n}=79)$ & $\mathrm{AD}(\mathrm{n}=133)$ & $\mathrm{p}$ value \\
\hline AGE & $75 \pm 1$ & $78 \pm 1$ & 0.005 \\
MALE GENDER (\%) & 66 & 37 & 0.01 \\
EDUCATION & $10 \pm 1$ & $8 \pm 0$ & n.s. \\
MMSE & $22.9 \pm 0.5$ & $22.7 \pm 0.2$ & n.s. \\
NPI-total & $9 \pm 1$ & $6 \pm 2$ & n.s. \\
UPDRS-III & $18 \pm 1$ & $2 \pm 0$ & 0.00001
\end{tabular}

MMSE= Mini Mental State Examination; NPI= Neuropsychiatric Inventory; UPDRS-III=Unified Parkinson's Disease Rating Scale-III 
Table 2 EEG variables (mean \pm st.err.) and statistical results in the comparison between AD and DLB in anterior, temporal and posterior derivations.

\begin{tabular}{lccll} 
EEG variables & $\begin{array}{c}\text { DLB } \\
(\mathrm{n}=79)\end{array}$ & $\begin{array}{c}\text { AD } \\
(\mathrm{n}=133)\end{array}$ & \multicolumn{1}{c}{ Statistical results } \\
& \multicolumn{5}{c}{ Anterior derivations } \\
DF & $5.9 \pm 0.2$ & $7.3 \pm 0.2$ & $\mathrm{~F}(1,210)=19.8$ & $\mathrm{p}<10^{-4}$ \\
DFV & $1.4 \pm 0.2$ & $1.5 \pm 0.2$ & $\mathrm{~F}(1,210)=0.1$ & $\mathrm{n} . \mathrm{s}$. \\
FP delta & $24 \pm 1$ & $19 \pm 1$ & $\mathrm{n} . \mathrm{s}$. \\
FP theta & $16 \pm 1$ & $10 \pm 1$ & $\mathrm{~F}(3,630)=47.0$ & $\mathrm{n} . \mathrm{s}$. \\
FP pre-alpha & $45 \pm 2$ & $28 \pm 2$ & $\mathrm{p}<10^{-9}$ \\
FP alpha & $15 \pm 2$ & $42 \pm 2$ & $\mathrm{p}<10^{-9}$ \\
& \multicolumn{5}{c}{ Temporal derivations } & \\
DF & $6.7 \pm 0.1$ & $8.3 \pm 0.1$ & $\mathrm{~F}(1,210)=55.9$ & $\mathrm{p}<10-6$ \\
DFV & $0.7 \pm 0.1$ & $0.7 \pm 0.1$ & $\mathrm{~F}(1,210)=0.0$ & $\mathrm{n} . \mathrm{s}$ \\
FP delta & $11 \pm 1$ & $9 \pm 1$ & $\mathrm{n} . \mathrm{s}$ \\
FP theta & $11 \pm 1$ & $7 \pm 1$ & $\mathrm{~F}(3,630)=69.98$ & $\mathrm{n} . \mathrm{s}$ \\
FP pre-alpha & $59 \pm 2$ & $33 \pm 2$ & $\mathrm{p}<10^{-12}$ \\
FP alpha & $19 \pm 2$ & $52 \pm 2$ & $\mathrm{p}<10^{-12}$ \\
& \multicolumn{5}{c}{ Posterior derivations } & \\
DF & $6.9 \pm 0.1$ & $8.7 \pm 0.1$ & $\mathrm{~F}(1,210)=71.5$ & $\mathrm{p}<10^{-6}$ \\
DFV & $0.7 \pm 0.1$ & $0.4 \pm 0.1$ & $\mathrm{~F}(1,210)=4.0$ & $\mathrm{p}<0.05$ \\
FP delta & $11 \pm 1$ & $7 \pm 1$ & & $\mathrm{n} . \mathrm{s}$ \\
FP theta & $13 \pm 1$ & $7 \pm 1$ & $\mathrm{~F}(3,630)=85.8$ & $\mathrm{n} . \mathrm{s}$ \\
FP pre-alpha & $54 \pm 2$ & $27 \pm 2$ & $\mathrm{p}<10^{-12}$ \\
FP alpha & $22 \pm 3$ & $60 \pm 2$ & & $\mathrm{p}<10^{-12}$ \\
\hline
\end{tabular}

$\mathrm{EEG}=$ electroencephalogram; $\mathrm{DLB}=$ Dementia with Lewy Bodies; $\mathrm{AD}=$ Alzeimer's Disease; $\mathrm{DF}=$ Dominant Frequency DFV= DF variability; FP= Frequency Prevalence. 
Table 3 Cut-off values provided by ROC analysis in all derivations, together with sensitivity (Sens), specificity (Spec), positive predictive value (PPV) and negative predictive value (NPV) for each EEG variable for the comparison between DLB and AD groups.

Cut-off values

Sens Spec PPV NPV

Anterior derivations

$\mathrm{DF}<7.3 \mathrm{~Hz}$

$\mathrm{DFV}>1.3$

FP pre-alpha $>29.4 \%$

FP alpha $<27.6 \%$

CSA pattern $>2$

Temporal derivations

$\mathrm{DF}<7.8 \mathrm{~Hz}$

$\mathrm{DFV}>3.3 \mathrm{~Hz}$

FP pre-alpha $>36.8 \mathrm{~Hz}$

FP alpha $<27.9 \%$

CSA pattern $>2$

Posterior derivations

$\mathrm{DF}<7.8 \mathrm{~Hz}$

$\mathrm{DFV}>2.2 \mathrm{~Hz}$

$84 \% \quad 59 \% \quad 55 \% \quad 86 \%$

$42 \% \quad 66 \% \quad 42 \% \quad 66 \%$

$84 \% \quad 61 \% \quad 56 \% \quad 86 \%$

$86 \% \quad 65 \% \quad 60 \% \quad 89 \%$

$97 \% \quad 41 \% \quad 49 \% \quad 96 \%$

$89 \% \quad 62 \% \quad 58 \% \quad 90 \%$

$9 \% \quad 95 \% \quad 50 \% \quad 64 \%$

$86 \% \quad 63 \% \quad 58 \% \quad 88 \%$

$76 \% \quad 80 \% \quad 69 \% \quad 85 \%$

$71 \% \quad 79 \% \quad 67 \% \quad 82 \%$

$80 \% \quad 72 \% \quad 63 \% \quad 86 \%$

$9 \% \quad 97 \% \quad 64 \% \quad 64 \%$ 
FP pre-alpha $>32.7 \%$

FP alpha $<40.7 \%$

CSA pattern $>2$
$85 \% \quad 68 \% \quad 61 \% \quad 88 \%$

$82 \% \quad 77 \% \quad 68 \% \quad 88 \%$

$67 \% \quad 83 \% \quad 71 \% \quad 81 \%$

$\mathrm{DF}=$ Dominant Frequency; $\mathrm{DFV}=\mathrm{DF}$ variability; $\mathrm{FP}=$ frequency prevalence; $\mathrm{CSA}=\mathrm{Compressed}$ Spectral Array 
Figure 1
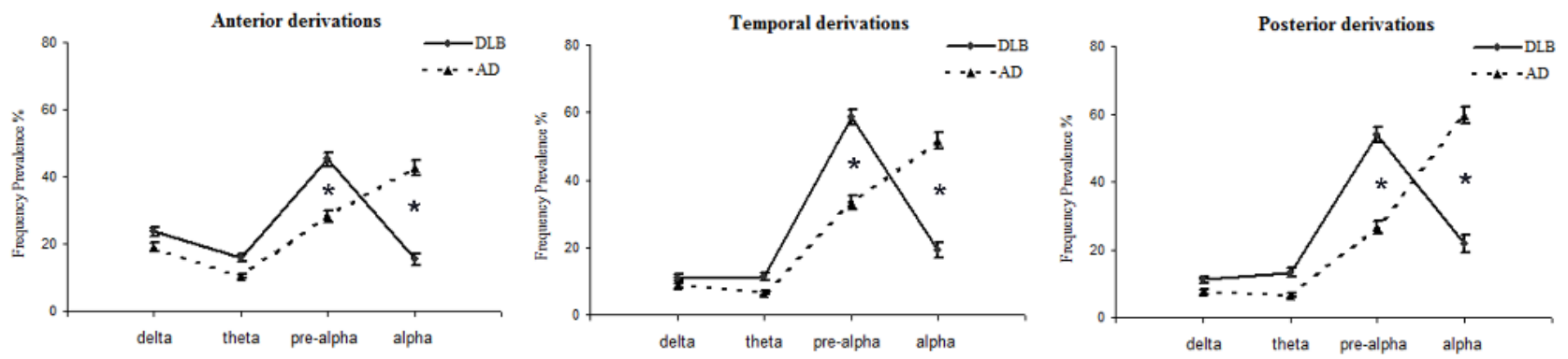
Figure 2
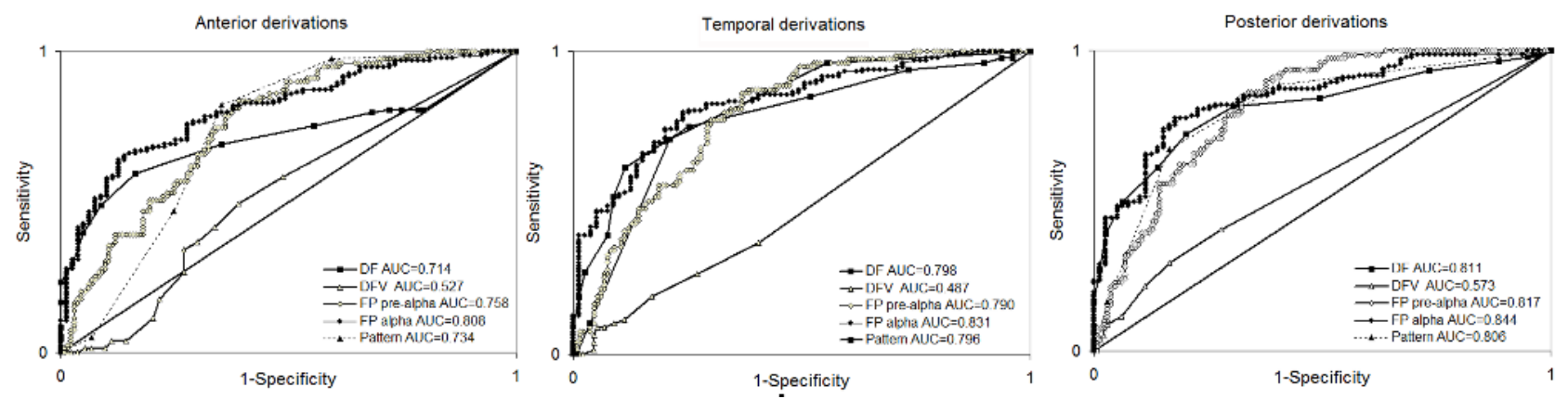
Figure legends

Fig. 1 Frequency Prevalence for delta, theta, pre-alpha and alpha bands from anterior, temporal and posterior derivations in DLB and AD groups. Significant differences between the two groups were found for pre-alpha and alpha band (*).

Fig. 2 ROC curves for dominant frequency (DF), dominant frequency variability (DFV), frequency prevalence (FP) in the pre-alpha and alpha bands from anterior, temporal and posterior derivations. Accuracy of each EEG variable to separate DLB from AD groups is measured by the area under each ROC curve. Area Under Curve (AUC) values shown in the inset highlight that the best EEG discriminating variable is $\mathrm{FP}$ in the alpha band (AUC $=0.808,0.831$ and 0.844 for anterior, temporal and posterior derivation respectively). 


\section{Supplementary material}

\section{Supplementary figure 1}
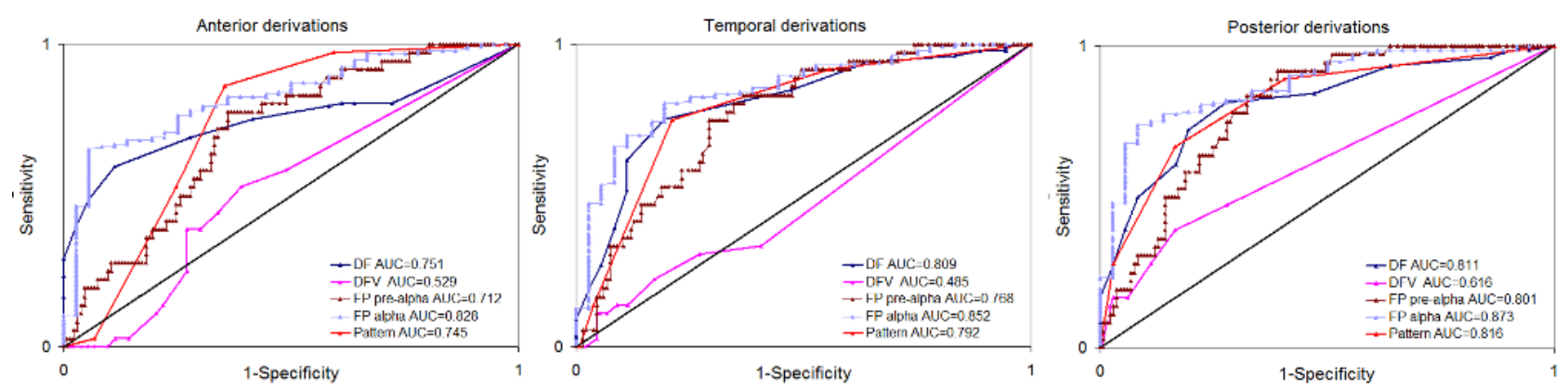

ROC curves for dominant frequency (DF), dominant frequency variability (DFV), frequency prevalence (FP) in the pre-alpha and alpha bands from anterior, temporal and posterior derivations. Accuracy of each EEG variable to separate 36 DLB patients with positive FP-BETA CIT scan from AD patient is measured by the area under each ROC curve. Area Under Curve (AUC) values shown in the inset highlight that the best EEG discriminating variable is FP in the alpha band (AUC $=0.828,0.852$ and 0.873 for anterior, temporal and posterior derivation respectively). 


\section{Supplementary Table 1}

Demographic and clinical characteristics (mean \pm S.E.) of each center separately.

\begin{tabular}{|c|c|c|c|c|c|c|c|c|}
\hline & \multicolumn{2}{|c|}{$\begin{array}{c}\text { Clinical Neurology } \\
\text { (Italy) }\end{array}$} & \multicolumn{2}{|c|}{$\begin{array}{c}\text { University Medical } \\
\text { Centre (Slovenia) }\end{array}$} & \multicolumn{2}{|c|}{$\begin{array}{l}\text { Campus for Ageing } \\
\text { and Vitality (UK) }\end{array}$} & \multicolumn{2}{|c|}{$\begin{array}{l}\text { Karolinska Univ. } \\
\text { Hospital (Sweden) }\end{array}$} \\
\hline & $\begin{array}{c}\text { DLB } \\
(n=16)\end{array}$ & $\underset{(n=110)}{A D}$ & $\begin{array}{l}\text { DLB } \\
(\mathrm{n}=7)\end{array}$ & $\begin{array}{c}\mathrm{AD} \\
(\mathrm{n}=0)\end{array}$ & $\begin{array}{c}\text { DLB } \\
(\mathrm{n}=23)\end{array}$ & $\begin{array}{c}\mathrm{AD} \\
(\mathrm{n}=23)\end{array}$ & $\begin{array}{l}\text { DLB } \\
(\mathrm{n}=33)\end{array}$ & $\begin{array}{c}\mathrm{AD} \\
(\mathrm{n}=0)\end{array}$ \\
\hline AGE & $74 \pm 1$ & $78 \pm 1$ & $75 \pm 2$ & - & $76 \pm 1$ & $76 \pm 2$ & $73 \pm 2$ & - \\
\hline $\begin{array}{l}\text { MALE } \\
\text { GENDER (\%) }\end{array}$ & $50 \%$ & $30 \%$ & $71 \%$ & - & $78 \%$ & $70 \%$ & $63 \%$ & - \\
\hline EDUCATION & $8 \pm 1$ & $8 \pm 0$ & $12 \pm 2$ & - & $10 \pm 1$ & $11 \pm 0$ & - & - \\
\hline MMSE & $24.1 \pm 0.7$ & $23.2 \pm 0.2$ & $20.0 \pm 0.9$ & - & $23.1 \pm 0.8$ & $20.0 \pm 0.9$ & $23.0 \pm 0.9$ & - \\
\hline NPI-total & - & - & - & - & $9 \pm 1$ & $6 \pm 1$ & - & - \\
\hline CAF & - & - & - & - & $3 \pm 1$ & $0 \pm 0$ & - & - \\
\hline ODFA & - & - & - & - & $2 \pm 1$ & $2 \pm 1$ & - & - \\
\hline UPDRS-III & $17 \pm 2$ & - & $27 \pm 2$ & - & $16 \pm 2$ & $2 \pm 0$ & - & - \\
\hline $\begin{array}{l}\text { RBD } \\
\text { (present \%) }\end{array}$ & $44 \%$ & - & $86 \%$ & - & $50 \%$ & $5 \%$ & $80 \%$ & - \\
\hline
\end{tabular}

$\mathrm{MMSE}=$ Mini Mental State Examination; NPI= Neuropsychiatric Inventory; $\mathrm{CAF}=\mathrm{Clinician}$

Assessment of Fluctuations; ODFA= One-Day Assessment of Fluctuations; UPDRS-III= Unified

Parkinson's Disease Rating Scale-III; RBD= REM sleep Behaviour Disorder. 


\section{Supplementary Table 2}

EEG variables (mean \pm S.E.) in all derivations and statistical results in the comparison between the previous (Bonanni et al., 2008) and the present study.

\begin{tabular}{|c|c|c|c|c|c|c|c|c|}
\hline \multirow[b]{2}{*}{ Variables } & \multicolumn{4}{|c|}{ DLB } & \multicolumn{4}{|c|}{$\mathrm{AD}$} \\
\hline & $\begin{array}{c}\text { Bonanni } \\
\text { et al } \\
(\mathrm{n}=36)\end{array}$ & $\begin{array}{c}\text { Present } \\
\text { study } \\
(\mathrm{n}=79)\end{array}$ & \multicolumn{2}{|c|}{ Statistical results } & $\begin{array}{c}\text { Bonanni } \\
\text { et al } \\
(\mathrm{n}=40)\end{array}$ & $\begin{array}{c}\text { Present } \\
\text { study } \\
(\mathrm{n}=133)\end{array}$ & \multicolumn{2}{|c|}{ Statistical results } \\
\hline \multicolumn{9}{|c|}{ ANTERIOR DERIVATIONS } \\
\hline DF & $7.0 \pm 0.3$ & $5.9 \pm 0.2$ & $\mathrm{~F}(1,113)=9.9$ & $\mathrm{p}=0.002$ & $8.0 \pm 0.2$ & $7.3 \pm 0.2$ & $F(1,171)=2.4$ & n.s. \\
\hline DFV & $2.8 \pm 0.3$ & $1.4 \pm 0.2$ & $F(1,113)=18.5$ & $\mathrm{p}=4 * 10^{-4}$ & $1.7 \pm 0.2$ & $1.5 \pm 0.2$ & $\mathrm{~F}(1,171)=0.2$ & n.s. \\
\hline FP delta & $10 \pm 1$ & $24 \pm 1$ & \multirow{4}{*}{$F(3,339)=16.6$} & $\mathrm{p}=10^{-6}$ & $8 \pm 1$ & $19 \pm 1$ & \multirow{4}{*}{$F(3,513)=35.4$} & $\mathrm{p}=0.008$ \\
\hline FP theta & $8 \pm 1$ & $16 \pm 1$ & & $\mathrm{p}=0.05$ & $13 \pm 1$ & $10 \pm 1$ & & n.s. \\
\hline FP pre-alpha & $53 \pm 2$ & $45 \pm 2$ & & $\mathrm{p}=0.03$ & $8 \pm 1$ & $28 \pm 2$ & & $\mathrm{p}<10^{-9}$ \\
\hline FP alpha & $25 \pm 2$ & $15 \pm 2$ & & $\mathrm{p}=0.004$ & $69 \pm 1$ & $42 \pm 2$ & & $\mathrm{p}<10^{-9}$ \\
\hline \multicolumn{9}{|l|}{ CSA Pattern } \\
\hline 1 & $0.0 \%$ & $2.5 \%$ & & & $75.0 \%$ & $40.6 \%$ & & \\
\hline 2 & $25.0 \%$ & $15.2 \%$ & & & $10.0 \%$ & $24.1 \%$ & & \\
\hline 3 & $36.1 \%$ & $35.4 \%$ & & & $0.0 \%$ & $10.5 \%$ & & \\
\hline 4 & $27.8 \%$ & $41.8 \%$ & & & $10.0 \%$ & $18.0 \%$ & & \\
\hline 5 & $11.1 \%$ & $5.1 \%$ & & & $5.0 \%$ & $6.8 \%$ & & \\
\hline \multicolumn{9}{|c|}{ TEMPORAL DERIVATIONS } \\
\hline $\mathrm{DF}$ & $6.8 \pm 0.3$ & $6.7 \pm 0.1$ & $F(1,113)=0.04$ & n.s. & $8.0 \pm 0.1$ & $8.3 \pm 0.1$ & $\mathrm{~F}(1,171)=1.0$ & n.s. \\
\hline DFV & $1.9 \pm 0.2$ & $0.7 \pm 0.1$ & $F(1,113)=23.0$ & $\mathrm{p}=10^{-5}$ & $1.3 \pm 0.1$ & $0.7 \pm 0.1$ & $\mathrm{~F}(1,171)=8.2$ & $\mathrm{p}=0.005$ \\
\hline FP delta & $9 \pm 1$ & $11 \pm 1$ & & n.s. & $8 \pm 1$ & $9 \pm 1$ & & n.s. \\
\hline FP theta & $8 \pm 1$ & $11 \pm 1$ & \multirow{3}{*}{$\mathrm{F}(3,339)=1.8$} & n.s. & $13 \pm 1$ & $7 \pm 1$ & \multirow{3}{*}{$\mathrm{F}(3,513)=26.3$} & n.s. \\
\hline FP pre-alpha & $54 \pm 1$ & $59 \pm 2$ & & n.s. & $8 \pm 1$ & $33 \pm 2$ & & $\mathrm{p}<10^{-9}$ \\
\hline FP alpha & $24 \pm 1$ & $19 \pm 2$ & & n.s. & $69 \pm 1$ & $52 \pm 2$ & & $\mathrm{p}<10^{-6}$ \\
\hline \multicolumn{9}{|l|}{ CSA Pattern } \\
\hline 1 & $0.0 \%$ & $3.8 \%$ & & & $80.0 \%$ & $44.4 \%$ & & \\
\hline 2 & $25.0 \%$ & $25.3 \%$ & & & $5.0 \%$ & $34.6 \%$ & & \\
\hline 3 & $33.3 \%$ & $60.8 \%$ & & & $5.0 \%$ & $17.3 \%$ & & \\
\hline 4 & $30.6 \%$ & $10.1 \%$ & & & $5.0 \%$ & $3.0 \%$ & & \\
\hline 5 & $11.1 \%$ & $0.0 \%$ & & & $5.0 \%$ & $0.7 \%$ & & \\
\hline \multicolumn{9}{|c|}{ POSTERIOR DERIVATIONS } \\
\hline $\mathrm{DF}$ & $7.4 \pm 0.3$ & $6.9 \pm 0.1$ & $F(1,113)=3.5$ & n.s. & $8.3 \pm 0.1$ & $8.7 \pm 0.1$ & $\mathrm{~F}(1,171)=1.6$ & n.s. \\
\hline DFV & $1.8 \pm 0.2$ & $0.7 \pm 0.1$ & $F(1,113)=24.3$ & $\mathrm{p}=3 * 10-6$ & $1.1 \pm 0.1$ & $0.4 \pm 0.1$ & $F(1,171)=22.9$ & $\mathrm{p}=4 * 10-6$ \\
\hline FP delta & $7 \pm 1$ & $11 \pm 1$ & $F(3,339)=2.8$ & n.s. & $6 \pm 0$ & $7 \pm 1$ & $F(3,513)=17.9$ & n.s. \\
\hline FP theta & $10 \pm 1$ & $13 \pm 1$ & & n.s. & $11 \pm 1$ & $7 \pm 1$ & & n.s. \\
\hline FP pre-alpha & $61 \pm 1$ & $54 \pm 2$ & & n.s. & $6 \pm 1$ & $27 \pm 2$ & & $\mathrm{p}<10-9$ \\
\hline FP alpha & $19 \pm 1$ & $22 \pm 3$ & & n.s. & $74 \pm 1$ & $60 \pm 2$ & & $\mathrm{p}=9 * 10-5$ \\
\hline \multicolumn{9}{|l|}{ CSA Pattern } \\
\hline 1 & 0 & $11.4 \%$ & & & $100.0 \%$ & $59.4 \%$ & & \\
\hline 2 & $33.3 \%$ & $21.5 \%$ & & & $0.0 \%$ & $24.1 \%$ & & \\
\hline 3 & $25.0 \%$ & $50.6 \%$ & & & $0.0 \%$ & $13.5 \%$ & & \\
\hline 4 & $30.6 \%$ & $16.5 \%$ & & & $0.0 \%$ & $3.0 \%$ & & \\
\hline 5 & $11.1 \%$ & $0.0 \%$ & & & $0.0 \%$ & $0.0 \%$ & & \\
\hline
\end{tabular}


$\mathrm{DLB}=$ Dementia with Lewy Bodies; $\mathrm{AD}=$ Alzheimer's Disase; $\mathrm{DF}=$ Dominant frequency; $\mathrm{DFV}=$ DF variability; FP= Frequency Prevalence; $\mathrm{CSA}=$ Compressed Spectral Array. 
Supplementary Table 3 Sensitivity (Sens), specificity (Spec), positive predictive value (PPV) and negative predictive value (NPV) of EEG variables with cut-off values reported in the previous paper (Bonanni et al., 2008).

Bonanni et al. Anterior derivations Temporal derivations Posterior derivations

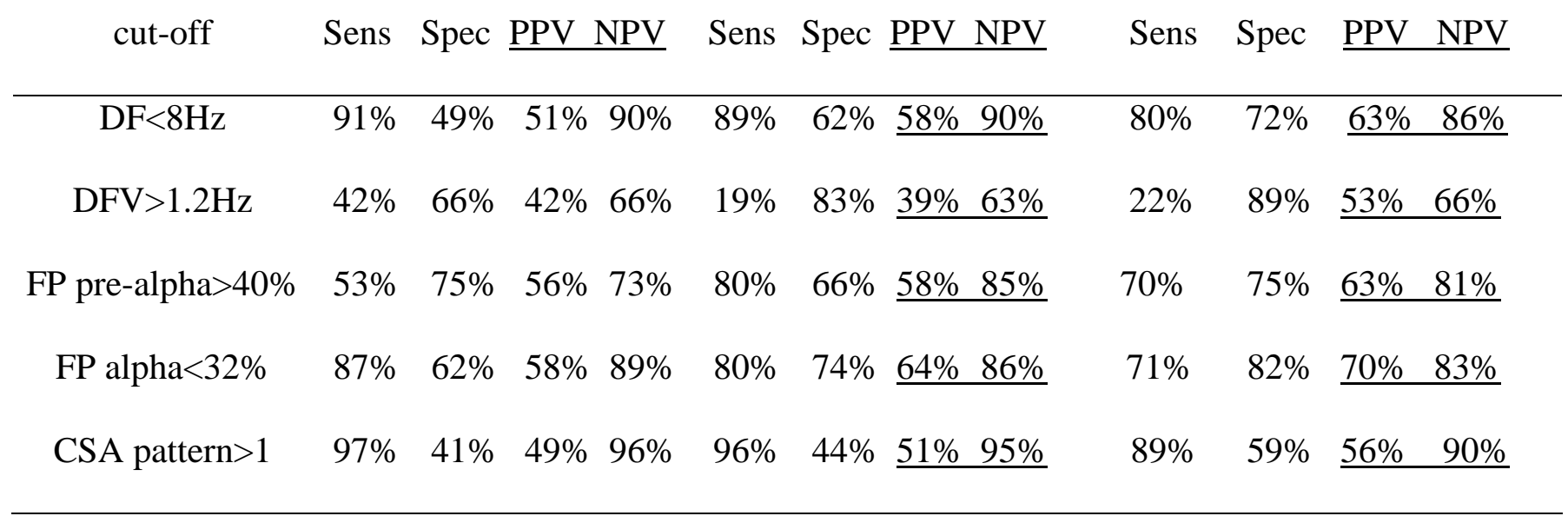

$\mathrm{DF}=$ Dominant Frequency DFV= DF variabilità; FP= Frequency Prevalence $\mathrm{CSA}=\mathrm{Compressed}$ Spectral Array 


\section{Supplementary Table 4}

EEG variables (mean \pm S.E.) and statistical results in the comparison between AD and 36 DLB patients with positive (123)I-FP-CIT SPECT scan.

\begin{tabular}{|c|c|c|c|c|}
\hline EEG variables & DLB & $\mathrm{AD}$ & \multicolumn{2}{|c|}{ Statistical results } \\
\hline & $(n=36)$ & $(n=133)$ & & \\
\hline & \multicolumn{4}{|c|}{ Anterior derivations } \\
\hline$\overline{\mathrm{DF}}$ & $5.4 \pm 0.3$ & $7.3 \pm 0.2$ & $\mathrm{~F}(1,167)=17.4$ & $\mathrm{p}<10^{-3}$ \\
\hline DFV & $1.4 \pm 0.3$ & $1.5 \pm 0.2$ & $\mathrm{~F}(1,167)=0.04$ & n.s. \\
\hline FP delta & $26 \pm 2$ & $19 \pm 1$ & \multirow{4}{*}{$F(3,501)=26.0$} & n.s. \\
\hline FP theta & $19 \pm 2$ & $10 \pm 1$ & & n.s. \\
\hline FP pre-alpha & $42 \pm 3$ & $28 \pm 2$ & & $\mathrm{p}<0.005$ \\
\hline FP alpha & $14 \pm 3$ & $42 \pm 2$ & & $\mathrm{p}<10^{-12}$ \\
\hline & \multicolumn{4}{|c|}{ Temporal derivations } \\
\hline$\overline{\mathrm{DF}}$ & $6.6 \pm 0.2$ & $8.3 \pm 0.1$ & $\mathrm{~F}(1,167)=34.8$ & $\mathrm{p}<10^{-6}$ \\
\hline DFV & $0.8 \pm 0.2$ & $0.7 \pm 0.1$ & $F(1,167)=0.1$ & n.s. \\
\hline FP delta & $13 \pm 2$ & $9 \pm 1$ & \multirow{4}{*}{$F(3,501)=38.8$} & n.s \\
\hline FP theta & $14 \pm 2$ & $7 \pm 1$ & & n.s \\
\hline FP pre-alpha & $57 \pm 3$ & $33 \pm 2$ & & $\mathrm{p}<10^{-9}$ \\
\hline FP alpha & $17 \pm 3$ & $52 \pm 2$ & & $\mathrm{p}<10^{-12}$ \\
\hline & \multicolumn{4}{|c|}{ Posterior derivations } \\
\hline $\mathrm{DF}$ & $6.8 \pm 0.2$ & $8.7 \pm 0.1$ & $\mathrm{~F}(1,167)=39.8$ & $\mathrm{p}<10^{-6}$ \\
\hline DFV & $0.9 \pm 0.2$ & $0.4 \pm 0.1$ & $F(1,167)=8.3$ & $\mathrm{p}<0.005$ \\
\hline FP delta & $13 \pm 2$ & $7 \pm 1$ & & n.s \\
\hline FP theta & $16 \pm 2$ & $7 \pm 1$ & $E(3501)-503$ & n.s \\
\hline FP pre-alpha & $52 \pm 3$ & $27 \pm 2$ & $F(3,501)=50.3$ & $\mathrm{p}<10^{-12}$ \\
\hline FP alpha & $19 \pm 4$ & $60 \pm 2$ & & $\mathrm{p}<10^{-12}$ \\
\hline
\end{tabular}

(123)I-FP-CIT SPECT = (123)I-FP-CIT Single photon emission computed tomography;

$\mathrm{EEG}=$ electroencephalogram; $\mathrm{DLB}=$ Dementia with Lewy Bodies; $\mathrm{AD}=$ Alzheimer's Disease; $\mathrm{DF}=$ Dominant Frequency; DFV= DF variability; FP= Frequency Prevalence. 
Supplementary Table 5 Cut-off values provided by ROC analysis in all derivations, together with sensitivity (Sens), specificity (Spec), positive predictive value (PPV) and negative predictive value (NPV) of each EEG variable for the comparison between 36 DLB patients with positive (123)I-FPCIT SPECT scan and AD groups.

Cut-off values

Sens Spec PPV NPV

Anterior derivations

$\mathrm{DF}<7.3 \mathrm{~Hz}$

$\mathrm{DFV}>2.3$

FP pre-alpha $>31.2 \%$

FP alpha $<27.6 \%$

CSA pattern $>2$

Temporal derivations

$\mathrm{DF}<7.3 \mathrm{~Hz}$

$\mathrm{DFV}>3.8$

FP pre-alpha $>39.8 \%$

FP alpha $<26.4 \%$

CSA pattern $>2$

Posterior derivations
$89 \% \quad 59 \% \quad 37 \% \quad 95 \%$

$39 \% \quad 73 \% \quad 28 \% \quad 82 \%$

$78 \% \quad 64 \% \quad 37 \% \quad 91 \%$

$94 \% \quad 65 \% \quad 43 \% \quad 98 \%$

$86 \% \quad 65 \% \quad 40 \% \quad 95 \%$

$81 \% \quad 75 \% \quad 47 \% \quad 93 \%$

$11 \% \quad 95 \% \quad 40 \% \quad 80 \%$

$81 \% \quad 65 \% \quad 39 \% \quad 93 \%$

$81 \% \quad 80 \% \quad 53 \% \quad 94 \%$

$75 \% \quad 79 \% \quad 49 \% \quad 92 \%$

$\mathrm{DF}<7.3 \mathrm{~Hz}$

$72 \% \quad 81 \% \quad 51 \% \quad 92 \%$ 
$\mathrm{DFV}>2.3$

FP pre-alpha $>25.7 \%$

FP alpha $<48.8 \%$

CSA pattern $>2$
$17 \%$

$97 \%$

$60 \%$

$81 \%$

$92 \% \quad 61 \% \quad 39 \% \quad 96 \%$

$94 \% \quad 68 \% \quad 44 \% \quad 98 \%$

$67 \% \quad 83 \% \quad 52 \% \quad 90 \%$

$\mathrm{ROC}=$ Receiver Operating Characteristic $\mathrm{DLB}=$ Dementia with Lewy Bodies; $\mathrm{AD}=$ Alzheimer's

Disease; (123)I-FP-CIT SPECT = (123)I-FP-CIT Single photon emission computed tomography;

$\mathrm{EEG}=$ electroencephalogram; $\mathrm{DF}=$ Dominant Frequency DFV= DF variability $; \mathrm{FP}=$ Frequency

Prevalence; $\mathrm{CSA}=$ Compressed Spectral Array.

\section{Supplementary Table 6}

EEG variables (mean \pm st.err.) and results of the statistical comparisons between AD patients with and without drug treatment withdrawal before EEG.

\begin{tabular}{ccccc}
\hline EEG variables & $\begin{array}{c}\text { Drug-on } \\
(\mathrm{n}=23)\end{array}$ & $\begin{array}{c}\text { Drug-off } \\
(\mathrm{n}=110)\end{array}$ & \multicolumn{2}{c}{ Statistical results } \\
\hline $\begin{array}{c}\text { DF posterior } \\
7.7 \pm 0.4\end{array}$ & $8.9 \pm 0.1$ & $\mathrm{~F}(1,131)=10.6$ & $\mathrm{p}=0.001$ \\
DF anterior & $4.5 \pm 0.5$ & $7.9 \pm 0.2$ & $\mathrm{~F}(1,131)=46.4$ & $\mathrm{p}<10^{-4}$ \\
$\begin{array}{c}\text { DF temporal } \\
\text { DFV anterior }\end{array}$ & $2.5 \pm 0.4$ & $8.5 \pm 0.1$ & $\mathrm{~F}(1,131)=6.9$ & $\mathrm{p}=0.01$ \\
$\quad \begin{array}{l}\text { FP alpha } \\
\text { posterior }\end{array}$ & $38.2 \pm 5.5$ & $64.0 \pm 2.5$ & $\mathrm{~F}(3,393)=13.3$ & $\mathrm{p}<10^{-7}$ \\
$\begin{array}{c}\text { FP delta } \\
\text { anterior }\end{array}$ & $39.7 \pm 2.2$ & $14.6 \pm 1.1$ & & $\mathrm{p}<10^{-8}$ \\
$\begin{array}{c}\text { FP alpha } \\
\text { anterior }\end{array}$ & $14.2 \pm 2.5$ & $48.4 \pm 2.4$ & $\mathrm{~F}(3,393)=33.5$ & \\
$\begin{array}{c}\text { FP alpha } \\
\text { temporal }\end{array}$ & $32.1 \pm 5.0$ & $55.7 \pm 2.4$ & $\mathrm{~F}(3,393)=10.6$ & $\mathrm{p}<10^{-7}$ \\
$\begin{array}{c}\text { CSA pattern } \\
\text { posterior }\end{array}$ & 2 & 1 & $\mathrm{~F}(1,131)=14.4$ & $\mathrm{p}=0.001$ \\
$\begin{array}{c}\text { CSA pattern } \\
\text { anterior }\end{array}$ & 4 & 2 & $\mathrm{~F}(1,131)=72.3$ & $\mathrm{p}<10^{-4}$ \\
CSA pattern & 3 & 2 & $\mathrm{~F}(1,131)=18.0$ & $\mathrm{p}<10^{-4}$ \\
\hline
\end{tabular}


temporal

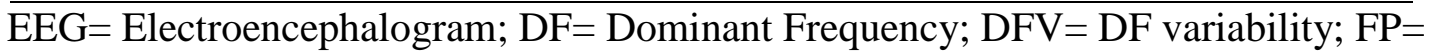
Frequency Prevalence; CSA= Compressed Spectral Array.

Supplementary Table 7 Demographic and clinical characteristics (mean \pm S.E.) of the subgroups matched for age, sex, education, MMSE and NPI-total.

\begin{tabular}{llll} 
& DLB $(\mathrm{n}=79)$ & $\mathrm{AD}(\mathrm{n}=79)$ & $\mathrm{p}$ value \\
\hline AGE & $75 \pm 1$ & $75 \pm 1$ & n.s. \\
MALE GENDER (\%) & 66 & 66 & n.s. \\
EDUCATION & $10 \pm 1$ & $9 \pm 1$ & n.s. \\
MMSE & $22.9 \pm 0.5$ & $22.7 \pm 0.3$ & n.s. \\
NPI-total & $9 \pm 1$ & $6 \pm 1$ & n.s. \\
UPDRS-III & $18 \pm 1$ & $2 \pm 0$ & 0.00001
\end{tabular}

MMSE = Mini Mental State Examination; NPI= Neuropsychiatric Inventory; UPDRS-III=Unified Parkinson's Disease Rating Scale-III 
Supplementary Table 8 EEG variables (mean \pm st.err.) and statistical results in the comparison between DLB and AD subgroup in anterior, temporal and posterior derivations.

\begin{tabular}{lcccc} 
EEG variables & DLB & AD & \multicolumn{1}{c}{ Statistical results } \\
& $(\mathrm{n}=79)$ & $(\mathrm{n}=79)$ & \\
& \multicolumn{5}{c}{ Anterior derivations } \\
DF & $5.9 \pm 0.2$ & $7.0 \pm 0.3$ & $\mathrm{~F}(1,156)=9.9$ & $\mathrm{p}<0.002$ \\
DFV & $1.4 \pm 0.2$ & $1.5 \pm 0.2$ & $\mathrm{~F}(1,156)=0.1$ & n.s. \\
FP delta & $24 \pm 1$ & $21 \pm 2$ & n.s. \\
FP theta & $16 \pm 1$ & $12 \pm 1$ & $\mathrm{n} . \mathrm{s}$. \\
FP pre-alpha & $45 \pm 2$ & $28 \pm 2$ & & $\mathrm{p}<10^{-9}$ \\
FP alpha & $15 \pm 2$ & $39 \pm 3$ & & $\mathrm{p}<10^{-9}$
\end{tabular}

Temporal derivations

$\begin{array}{lccll}\text { DF } & 6.7 \pm 0.1 & 8.3 \pm 0.2 & \mathrm{~F}(1,156)=49.0 & \mathrm{p}<10^{-6} \\ \text { DFV } & 0.7 \pm 0.1 & 0.7 \pm 0.2 & \mathrm{~F}(1,210)=0.0 & \text { n.s } \\ \text { FP delta } & 11 \pm 1 & 9 \pm 1 & & \text { n.s } \\ \text { FP theta } & 11 \pm 1 & 7 \pm 1 & & \text { n.s } \\ \text { FP pre-alpha } & 59 \pm 2 & 34 \pm 3 & \mathrm{~F}(3,468)=51.3 & \mathrm{p}<10^{-12} \\ \text { FP alpha } & 19 \pm 2 & 49 \pm 3 & & \mathrm{p}<10^{-12}\end{array}$

Posterior derivations
$\mathrm{DF}$
$6.9 \pm 0.1$
$8.5 \pm 0.2$
$\mathrm{F}(1,156)=47.9$
$\mathrm{p}<10^{-6}$
DFV
$0.7 \pm 0.1$
$0.3 \pm 0.1$
$\mathrm{F}(1,156)=5.6$
$\mathrm{p}<0.02$
FP delta
$11 \pm 1 \quad 8 \pm 1$
n.s
FP theta
$13 \pm 1$
$7 \pm 1$
$\mathrm{F}(3,468)=61.0$
n.s
FP pre-alpha
$54 \pm 2$
$27 \pm 3$
$\mathrm{p}<10^{-12}$ 

FP alpha
$22 \pm 3$
$57 \pm 3$
$\mathrm{p}<10^{-12}$

$\mathrm{EEG}=$ electroencephalogram; $\mathrm{DLB}=$ Dementia with Lewy Bodies; $\mathrm{AD}=$ Alzeimer's Disease;

$\mathrm{DF}=$ Dominant Frequency; DFV= DF variability; FP= Frequency Prevalence;

Supplementary Table 9 Cut-off values provided by ROC analysis in all derivations, together with sensitivity (Sens), specificity (Spec), positive predictive value (PPV), negative predictive value (NPV) and area under the curve (AUC) for each EEG variable in the comparison between DLB $(\mathrm{n}=79)$ and $\mathrm{AD}$ subgroup $(\mathrm{n}=79)$.

Cut-off values Sen

Spec

PPV NPV

AUC

Anterior derivations

$\mathrm{DF}<7.3 \mathrm{~Hz}$

$84 \% \quad 56 \% \quad 65 \% \quad 77 \% \quad 0.675$

DFV $>2.3$

$\begin{array}{lllll}34 \% & 72 \% & 55 \% & 52 \% & 0.529\end{array}$

FP pre-alpha $>29.4 \%$

$\begin{array}{lllll}84 \% & 63 \% & 69 \% & 79 \% & 0.768\end{array}$

FP alpha $<30.2 \%$

$\begin{array}{lllll}87 \% & 57 \% & 67 \% & 82 \% & 0.773\end{array}$

CSA pattern $>2$

$\begin{array}{lllll}82 \% & 54 \% & 64 \% & 75 \% & 0.670\end{array}$

Temporal derivations 
$\mathrm{DF}<7.3 \mathrm{~Hz}$

$\mathrm{DFV}>3.3 \mathrm{~Hz}$

FP pre-alpha $>35.6 \mathrm{~Hz}$

FP alpha $<26.9 \%$

CSA pattern $>2$

Posterior derivations

$\mathrm{DF}<7.8 \mathrm{~Hz}$

DFV $>2.3 \mathrm{~Hz}$

FP pre-alpha $>31.6 \%$

FP alpha $<40.7 \%$

CSA pattern $>1$
$75 \%$

$76 \%$

$76 \%$

$75 \%$

0.805

$9 \% \quad 95 \% \quad 64 \% \quad 51 \%$

0.487

$87 \%$

$62 \%$

$70 \%$

$83 \%$

0.785

$75 \%$

$77 \%$

$77 \% \quad 75 \%$

0.811

$71 \%$

$75 \%$

$74 \%$

$72 \%$

0.762

$\begin{array}{lllll}80 \% & 68 \% & 72 \% & 77 \% & 0.783\end{array}$

$\begin{array}{lllll}9 \% & 99 \% & 88 \% & 52 \% & 0.580\end{array}$

$\begin{array}{lllll}86 \% & 68 \% & 73 \% & 83 \% & 0.809\end{array}$

$\begin{array}{lllll}82 \% & 75 \% & 76 \% & 81 \% & 0.829\end{array}$

$89 \% \quad 62 \% \quad 70 \% \quad 84 \%$

0.799

$\mathrm{DF}=$ Dominant Frequency $; \mathrm{DFV}=\mathrm{DF}$ variability $; \mathrm{FP}=$ frequency prevalence $; \mathrm{CSA}=\mathrm{Compressed}$ Spectral Array 